\title{
Achieving Glycaemic Control with Concentrated Insulin in Patients with Type 2 Diabetes
}

\section{Glycaemic Control with Concentrated Insulin in Type 2 Diabetes}

Dr Sudesna Chatterjee MBBS MD FRCP (Corresponding Author), Previously Consultant Diabetologist, University Hospitals of Leicester NHS Trust, Senior Clinical Researcher, University of Leicester, Leicester, UK, Currently Medical Director UK and Ireland, Abbott Diabetes Care, Abbott Laboratories, Maidenhead, UK. Sudesna.chatterjee@abbott.com

Prof Kamlesh Khunti FRCGP FRCP MDPhD FMedSci, Diabetes Research Centre, University of Leicester, Leicester, UK.

Prof Melanie J Davies CBE MBChB MD FRCP FRCGP FMedSci, Professor of Diabetes Medicine and NIHR Senior Investigator Emeritus, Diabetes Research Centre, University of Leicester, Leicester, UK. 


\section{Abstract}

The recent introduction of the second generation long-acting analogue insulins degludec and insulin glargine U300 have increased the choice of basal insulin therapy for patients with type 2 diabetes. The pharmacokinetic and pharmacodynamic properties of these insulins result in a flatter profile which lasts over 24 hours and provides an increased window of administration of six hours once daily. Large scale multicentre randomised clinical trial programmes (BEGIN for degludec U100 and U200 and EDITION for glargine U300) evaluating these insulin therapies against glargine U100 have demonstrated that they are either non-inferior or superior for glycaemic efficacy and safety but less likely to result in severe or nocturnal hypoglycaemia than glargine U100. The disposable pen devices for these insulins have been designed with patient satisfaction and convenience in mind. No concerns have arisen with adverse events with insulin analogues or cardiovascular safety from the ORIGIN and DEVOTE trials. As they demonstrate equivalent glycaemic efficacy to other basal insulins, they should be considered more in selected patient groups including those with recurrent or increased risk of hypoglycaemia, especially severe or nocturnal episodes, in the elderly or those living alone, and in patients with multiple co-morbidities such as cardiovascular or renal disease.

\section{Key Points}

- Second generation basal insulin analogues have demonstrated equivalent glycaemic efficacy to earlier basal insulin therapies but may result in lower risk of hypoglycaemia.

- Selected patient groups at increased risk of hypoglycaemia such as elderly, those living alone or with multiple co-morbidities including cardiovascular or renal disease may be considered for treatment with insulin degludec or glargine U300.

\section{Introduction}

\subsection{Background and Rationale for Development of Concentrated Insulin}

Since the discovery of insulin by Banting and Best in 1921, ${ }^{1}$ there has been a continuous process in improved development of insulin therapy. ${ }^{2}$ Near physiological insulin replacement improves glycaemic excursions and reduces microvascular and macrovascular complications in people with diabetes. ${ }^{3}$ Basal insulin therapy is currently recommended as an option following metformin when glycaemic targets are not reached in patients with type 2 diabetes (T2DM) and in combination with dual oral or other injectable glucose-lowering therapy or as part of a basal bolus regimen. ${ }^{4}$ For insulin initiation, basal insulin is recommended in preference to pre-mixed or prandial insulins as glycaemic efficacy is not limited by excessive hypoglycaemia or weight gain as demonstrated in the 4T study. ${ }^{5}$ 
The ideal long-acting basal insulin has a relatively flat profile with minimal intra-individual and interindividual variability and without resulting in excessive hypoglycaemia and weight gain.

Long-acting basal insulins have been available for more than 50 years in the form of Neutral Protamine Hagedorn (NPH) insulin with the more recent introduction of analogue insulins such as glargine U100 (100units/ml) and detemir. A retrospective observational study of 25,489 patients with T2DM initiated on basal insulin therapy comparing initiation of insulin glargine U100 or detemir with NPH insulin found no difference in risk of hypoglycaemia-related emergency department visits or glycaemic efficacy. ${ }^{6}$

In the last five years, second generation ultra-long-acting highly concentrated basal insulins have been introduced namely degludec U100 and U200 (Tresiba ${ }^{\circledR}$, NovoNordisk) and insulin glargine U300 (Toujeo ${ }^{\circledR}$, Sanofi-Aventis) which is three times more concentrated than glargine U100. These new generation basal insulins have no action peak and both intra-individual and inter-individual variability are reduced compared with older long-acting insulins (Fig.1). Another ultra-long-acting basal insulin, PegLispro, demonstrated clinically relevant improvements in glycaemic efficacy with significant reduction in nocturnal hypoglycaemia compared to NPH insulin in phase 3 trials $^{7}$ but this was discontinued in 2017 due to adverse effects including insulin site reactions and abnormal liver transaminase and triglyceride levels. ${ }^{8}$

Effective insulin therapy improves glycaemic control and reduces the development and progression of complications. However, hypoglycaemia and weight gain are significant adverse effects of insulin therapy. With time, the pharmacokinetic profiles of basal insulins have improved leading to fewer peaks and troughs and variability which reduces the risk of hypoglycaemia and increases patient safety. Nevertheless, the relatively higher costs of the highly concentrated insulins need to be balanced against their benefits compared with more established basal insulins such as glargine, detemir and NPH insulin especially as $80 \%$ of people with T2DM live in low-to-middle income countries. ${ }^{9}$ Notably, insulin degludec can be up to $50-70 \%$ more expensive than other basal insulins and up to approximately $15 \%$ higher doses of insulin glargine 300 are required compared with insulin glargine U100 increasing overall cost. ${ }^{10}$

This review will describe the long-acting concentrated insulins degludec U100 and U200 and glargine U300 and discuss their place in the management of patients with T2DM.

\section{Insulin Degludec (Tresiba $\left.{ }^{\circledR}\right)$}

Insulin degludec has been approved for use in Europe since 2013 and the USA since 2015 and is also now widely available in Asia and Latin America. The ultra-long duration of action of degludec U100 
and $\mathrm{U} 200$ results from the stabilising action of low concentrations of phenol and increased albumin binding resulting in the formation of hexamers following subcutaneous injection which slowly break down into dimers and monomers prior to absorption into the bloodstream. ${ }^{11}$ The soluble multihexamers result from changes in the amino acid structure of insulin specifically deletion of the B30 threonine molecule and formation of a covalent linkage with glutamic acid between B29 lysine and a C16 fatty acid. ${ }^{2}$ Reassuringly it has been shown experimentally that degludec has a low mitogenic-to-metabolic potency ratio. ${ }^{12}$ The plasma half-life of degludec is 25 hours which is nearly double that of insulin glargine U100. ${ }^{13}$

\subsection{Glycaemic Efficacy}

There have been several open-label randomised controlled phase 3 trials to investigate insulin degludec U100 and U200 compared with insulin glargine U100 in patients with T2DM in both insulinnaïve populations and those already on insulin therapy (Table 1). ${ }^{14-18}$ In summary, the trials demonstrate non-inferiority for glycaemic efficacy parameters between degludec U100 or U200 and glargine U100.

The head-to-head BEGIN Basal-Bolus Type 2 study of degludec U100 with glargine U100 in T2DM demonstrated equal efficacy with superiority of degludec in reduction in nocturnal hypoglycaemia due in part to reduced intra-individual variability. ${ }^{14}$ In this 52 week phase 3 open label treat-to-target noninferiority trial of 1006 participants with T2DM randomly allocated to either degludec or glargine $\mathrm{U} 100$, there was an glycated haemoglobin ( $\mathrm{HbA1c}$ ) reduction at study end of $1.1 \%$ in the degludec arm and $1.2 \%$ in the glargine arm (estimated treatment difference [ETR] $0.08 \%, 95 \% \mathrm{Cl}-0.05$ to 0.21 ).

In the 52 week BEGIN Once Long trial of insulin-naïve participants on oral glucose lowering therapy except thiazolinediones randomised to either insulin degludec U100 or glargine U100, there was no difference in glycaemic efficacy between the two insulins in terms of HbA1c reduction or fasting plasma glucose (FPG) levels but there was a significant reduction in nocturnal hypoglycaemia rates with degludec. ${ }^{15}$ In the BEGIN Low Volume randomised controlled trial there were no significant differences in glycaemic efficacy ( $\mathrm{HbA1C}$ and FPG) or hypoglycaemia rates between insulin degludec U200 and glargine U100. ${ }^{16}$ In the BEGIN Once Asia trial, similar results were seen as with the BEGIN Once Long trial for non-inferior glycaemic efficacy between the two basal insulins although insulin degludec U200 was superior in reducing nocturnal hypoglycaemia. ${ }^{17}$

The SWITCH 2 cross-over study was a 16 week randomised clinical trial consisting of 721 patients with T2DM and at least one hypoglycaemia risk factor who were previously treated with basal insulin with or without glucose lowering therapy and where glycaemic efficacy was a secondary endpoint. ${ }^{18}$ The 
hypoglycaemia risk factors included at least one severe hypoglycaemic episode in the last 12 months, hypoglycaemia unawareness, moderate chronic renal impairment, insulin therapy for more than five years, or symptoms and/or blood glucose level of $\leq 3.9 \mathrm{mmol} / \mathrm{l}(70 \mathrm{mg} / \mathrm{dl})$ in the last 12 weeks. At study end, insulin degludec was non-inferior to glargine $\mathrm{U} 100$ in $\mathrm{HbA1c}$ reduction for treatment period 1 (7.06\% vs $6.98 \%$ respectively, $95 \% \mathrm{Cl}-0.04 \%$ to $0.23 \%, \mathrm{P}<0.001$ for noninferiority) and treatment period $2(7.08 \%$ vs $7.11 \%$ respectively, $-0.07 \%$ to $0.18 \%, p<0.001)$.

\subsection{Hypoglycaemia}

Hypoglycaemia affects the well-being and quality of life of people with diabetes and is also a highly feared side-effect of treatment which limits ability to achieve optimal glycaemic control. ${ }^{19}$ The consequences of hypoglycaemia such as falls, paramedic call-outs and hospital admissions can also overburden health service resources. Managing severe hypoglycaemia has been shown to be more expensive for insulin-treated T2DM patients than type 1 diabetes (T1DM) patients in three European countries. ${ }^{20}$ Nocturnal hypoglycaemia in particular can be particularly dangerous especially in people who live on their own or have reduced counter-regulatory responses such as the elderly. ${ }^{21} \mathrm{~A}$ large real world analysis observational study of 55,608 patients with T2DM in the USA showed that hypoglycaemia was experienced by up to $4.5 \%$ of people within 6 months of initiation with basal insulin resulting in treatment discontinuation and increased healthcare utilisation and costs such as hospitalisation. ${ }^{22}$

A pre-specified meta-analysis of the phase 3 programme of degludec studies has confirmed that the rates of overall and nocturnal confirmed hypoglycaemic events were $17 \%$ and $32 \%$ less frequent with insulin degludec compared with insulin glargine U100 at similar HbA1c concentrations. ${ }^{23}$ However the authors acknowledged that the open-label design and exclusion of participants with recurrent severe hypoglycaemia were limitations of the meta-analysis.

In the BEGIN Basal-Bolus Type 2 study, rates of severe hypoglycaemia were similar for the two basal insulins ( 0.06 vs 0.05 episodes per patient-year exposure degludec vs glargine), and the main difference was in rate of nocturnal confirmed hypoglycaemia for degludec vs glargine (1.4 vs 1.8 episodes per patient-year exposure; estimated rate ratio $0.75,0.58$ to $0.99, p<0.05$ ) and overall hypoglycaemia ( 11.1 vs 13.6 episodes per patient-year exposure, $0.82,0.69$ to $0.99, p<0.05$ ). ${ }^{14}$

Overall symptomatic hypoglycaemia was also less frequent with insulin degludec than with glargine U100 in the SWITCH 2 double blind randomised controlled 64 week cross-over trial comprising 721 participants with T2DM. ${ }^{18}$ Notably, to be recruited, participants had to have at least one of five hypoglycaemia risk factors including at least one severe hypoglycaemic episode in the last 12 months, moderate chronic renal failure (eGFR $30-59 \mathrm{ml} / \mathrm{min} / 1.73 \mathrm{~m}^{2}$ ), hypoglycaemic unawareness, insulin 
treatment duration $>5$ years or episode of hypoglycaemia (symptoms and/or blood glucose $\leq 3.9$ $\mathrm{mmol} / \mathrm{l}$ in the last 3 months. The primary endpoint of this trial was rate of overall symptomatic hypoglycaemia during the 16 week maintenance period which was either a severe externally adjudicated episode defined as requiring third-party assistance or a confirmed blood glucose of $<3.1 \mathrm{mmol} / \mathrm{l}$. In patients randomised to insulin degludec, the rate of overall symptomatic hypoglycaemia was 185.6 episodes vs 265.4 episodes in those on glargine U100 per 100 patient-years of exposure (estimated rate ratio $[E R R]=0.70,95 \% \mathrm{Cl} 0.61$ to $0.80, p<0.001$ ). For nocturnal hypoglycaemia, episodes were 55.2 for degludec vs 93.6 for insulin glargine U100 per 100 patientyears of exposure (ERR $0.58,0.46$ to $0.74, p<0.001$ ). However, there was no difference between the two insulins for severe hypoglycaemia during the maintenance period (ERR $0.54,0.21$ to $1.42, p=0.35$ ).

A systematic review has confirmed that there is a $10 \%$ lower insulin dose requirement with degludec compared with glargine U100 and detemir which may explain the reduction in hypoglycaemia. ${ }^{24}$ Posthoc analysis of SWITCH 2 demonstrated that lower doses of insulin degludec were required after 32 weeks of treatment compared with insulin glargine U100 $(p<0.001) .{ }^{18}$

The US Food and Drugs Administration (FDA) has been cautious about the evidence regarding reduction in nocturnal hypoglycaemia with insulin degludec compared with insulin glargine U100 on the basis of lack of consistency across trials in terms of hypoglycaemia definition and study populations as well as differences in pharmacokinetics and pharmacodynamics of the insulins. Moreover, a two hour extension of the nocturnal period minimised the difference in hypoglycaemia between these insulins. ${ }^{10}$

A systematic review and network meta-analysis of thirty-nine trials comprising 26,195 patients with T2DM found low and very low quality evidence that reduced risk of nocturnal hypoglycaemia was associated with Degludec U100 and U200 and glargine $300 .^{25}$

\subsection{Weight}

Weight gain is a significant unwanted side-effect of insulin therapy. In the BEGIN Basal Bolus Type 2 trial, mean weight gain was similar for both insulins at the end of the study with patients on degludec gaining $3.6 \mathrm{~kg}$ (SD $4.9 \mathrm{~kg}$ ) and patients on glargine U100 gaining $4.0 \mathrm{~kg}$ (SD $4.6 \mathrm{~kg}) .{ }^{14}$

Similarly, in the SWITCH 2 cross-over study, there was no significant difference in weight between insulin degludec and insulin glargine $\mathrm{U} 100$ in either treatment period which was $1.5 \mathrm{~kg}$ and $0.5 \mathrm{~kg}$ for degludec and $1.8 \mathrm{~kg}$ and $0.9 \mathrm{~kg}$ for glargine at ends of treatment period 1 and $2(p=0.32$ and $p=0.29$ respectively). ${ }^{18}$

\subsection{Cardiovascular Safety}


Since 2008, all new glucose-lowering therapies need to be tested in robust cardiovascular outcome safety trials as required by the FDA. More recently the results of the cardiovascular outcome study for degludec A Trial Comparing Cardiovascular Safety of Insulin Degludec Versus Insulin Glargine in Subjects with Type 2 Diabetes at High Risk of Cardiovascular Events (DEVOTE) has confirmed that degludec is non-inferior to insulin glargine U100 for cardiovascular safety based on the primary major adverse cardiovascular composite outcome of cardiovascular death, non-fatal myocardial infarction or non-fatal stroke (hazard ratio $0.91,95 \% \mathrm{Cl} 0.78$ to 1.06 ). ${ }^{26}$ In this study of 7637 patients with T2DM, participants were either over 50 years of age with pre-existing cardiovascular disease (CVD) or over 60 years of age with CVD risk factors, with a mean age of 65.0 years and a mean duration of T2DM of 16.4 years. A further notable finding was that use of degludec was associated with significantly lower rates of severe and nocturnal hypoglycaemia compared with glargine U100 (3.70 vs 6.25 events per 100 patient-years).

\section{Glargine U300 (Toujeo ${ }^{\circledR}$ )}

Glargine U300 was approved globally for use in T2DM in 2015. As a consequence of low intraindividual variability ranging between $17 \%$ and $35 \%$, glargine U300 has a relatively peakless profile and greater diurnal reproducibility. ${ }^{27}$

Glargine U300 (300 units $/ \mathrm{ml}$ ) is three time more concentrated than glargine U100 (100 units $/ \mathrm{ml}$ ) and this impacts on the pharmacokinetic and pharmacodynamics properties of the newer formulation. Key differences are in the size of the subcutaneous depot which for glargine U300 is two-thirds in volume and half the surface area of glargine U100. These effects lead to slower degradation of insulin molecules consequently retarding insulin absorption. The half-life of glargine U100 is 12 hours whereas for glargine U300 it is 19 hours. There is a six hour window for injecting glargine U300 while retaining glycaemic efficacy and this enables greater flexibility in dose timing for patients with T2DM.

\subsection{Glycaemic Efficacy}

Glargine U300 has been extensively evaluated in a programme of multicentre randomized clinical trials (EDITION) including people with T2DM in North and South America, Europe, South Africa, and Japan using glargine U100 as a comparator (Table 2)..$^{28-31}$ In the EDITION 1 trial ${ }^{28}$, eligible participants were on $\geq 42$ units/day of either NPH insulin or glargine U100 plus mealtime insulin (lispro, aspart, gliulisine), in EDITION $2^{29}$, participants were on basal insulin ( $\geq 42$ units/day) and oral glucose-lowering therapy and in EDITION $3^{30}$ participants were insulin-naïve. Finally, the Japanese population in the EDITION JP 2 trial were on basal insulin and oral glucose-lowering therapy for at least 6 months with no prespecified basal insulin dose. ${ }^{31}$ 
A patient-level meta-analysis of 2496 participants in the EDITION 1,2 and 3 studies identified that glargine U300 is non-inferior to glargine U100 for mean change in HbA1c at 6 months (each -1.02 (standard error 0.03$) \%$; least squares mean difference $0.00(95 \% \mathrm{Cl}-0.08$ to 0.07$) \%) .{ }^{32} \mathrm{~A}$ similar proportion reached $\mathrm{HbA} 1 \mathrm{c}$ target of $<7.0 \%$ at study end $36.2 \%$ for glargine U300 and $35.5 \%$ for glargine U100). Fasting plasma glucose decreased similarly with both insulin formulations (LS mean difference $0.21,95 \% \mathrm{Cl} 0.03$ to $0.40 \mathrm{mmol} / \mathrm{l})$.

In summary, there was no statistically significant difference between insulin glargine U100 and U300 in terms of glycaemic efficacy identified in the phase 3 trial programme.

\subsection{Hypoglycaemia}

In the pooled analysis of EDITION 1, 2 and 3 trials, lower rates of hypoglycaemia were seen with glargine U300 compared with glargine U100 throughout the 24 hour period. ${ }^{32}$ For insulin glargine U300, there were 15.22 events per participant-year for confirmed $(\leq 3.9 \mathrm{mmol} / \mathrm{l})$ or severe hypoglycaemia and for glargine U100 17.73 events per participant-year (rate ratio $0.86,95 \% \mathrm{Cl} 77$ to $0.97, p=0.0116)$, reflecting a $14 \%$ difference favouring glargine U300. Nocturnal hypoglycaemic episodes between 00.00 and 05.59 hours were fewer with glargine U300 but most events were reported between 0.600 and 14.00 hours with 8.14 events per participant -year for glargine U300 and 10.13 events per participant-year for glargine U100 especially between 06.00 and 10.00 hours. Episodes of severe hypoglycaemia were relatively few with 0.11 events per participant-year in both groups (rate ratio $0.98,95 \% \mathrm{Cl} 0.51$ to 1.86 ) equating to $28(2.3 \%)$ in the glargine U300 group and 33 (2.6\%) in the glargine U100 group (relative risk $0.85,95 \% \mathrm{Cl} 0.52$ to 1.39). There was no difference in hypoglycaemia rates between older participants aged $>65$ years and those in younger age groups.

In the pooled analysis of the EDITION 1, 2 and 3 trials, there was an increase in basal insulin dose of $0.85 \mathrm{U} / \mathrm{kg} /$ day with glargine $\mathrm{U} 300$ and $0.76 \mathrm{U} / \mathrm{kg} /$ day with glargine $\mathrm{U} 100$, which reflects a $12 \%$ increased dose with glargine U300. ${ }^{32}$ This is in contrast to insulin dose reduction seen in trials with degludec.

\subsection{Weight}

In the pooled analysis of the EDITION 1, 2 and 3 trials, less weight gain was seen with glargine U300 than with glargine U100 (LS mean difference $-0.28,95 \% \mathrm{Cl}-0.55$ to $-0.01, p=0.039$ ). ${ }^{32}$

\subsection{Cardiovascular Safety}

The Outcome Reduction with Initial Glargine Intervention (ORIGIN) trial which predates the FDA mandate for cardiovascular safety outcome trials, provides reassurance for the cardiovascular safety 
of glargine U300 based on data for glargine U100. ${ }^{33}$ The 6-year ORIGIN trial was also able to demonstrate that cancer risk was very low for glargine U100 and by extension glargine U300. Furthermore, the ORIGIN-GRACE substudy confirmed that glargine U100 was associated with a reduced progression in carotid-intima thickening which is a surrogate for cardiovascular disease. ${ }^{34}$

\section{Head to Head Studies}

\subsection{Randomised Trials}

The BRIGHT trial is the first reported head-to-head non-inferiority study between insulin glargine U300 and insulin degludec U100 in insulin-naïve T2DM patients. ${ }^{35}$ In this open-label 24 week parallel-group study, 929 participants with T2DM on any glucose-lowering agents including SGLT-2 inhibitors and GLP-1 receptor agonists were randomised to evening dosing of either long acting insulin with uptitration to maintain a FPG of $4.4-5.5 \mathrm{mmol} / \mathrm{l}(80-100 \mathrm{mg} / \mathrm{dL})$.

At study end there was no difference in the glycaemic improvement from baseline between insulin glargine U300 and degludec U100 (HbA1c 7.0\% [53mmol $/ \mathrm{mol}], \mathrm{p}<0.0001)$. In the active titration period, there was lower incidence and rate of hypoglycaemia over the 24 hour period with glargine U300, but there were no differences between the two insulins in the maintenance period (weeks 13 to 24) although hypoglycaemia was more likely in patients on sulphonylureas or meglitinides at screening. Apart from one episode of severe hypoglycaemia with glargine U300 there were no other significant adverse effects or safety issues for either insulin. At study end, absolute mean weight gain was $2.0 \pm 3.8 \mathrm{~kg}$ with glargine $\mathrm{U} 300$ and $2.3 \pm 3.6 \mathrm{~kg}$ with degludec U100.

In a small Japanese trial of 24 participants with T2DM randomised to either glargine U300 or degludec U100 where the primary endpoints were hypoglycaemia and mean percentage of time spent in target glucose range as assessed by flash glucose monitoring over 14 days, there was no significant difference between the insulins for glycaemic efficacy although insulin degludec was associated with significantly lower rates of nocturnal hypoglycaemia $(p=0.007) .{ }^{36}$ The same researchers found similar results in another 30 patients with T2DM when these insulins were compared for glycaemic efficacy and hypoglycaemia using continuous glucose monitoring over 5 days. ${ }^{37}$

These trials provide evidence that insulin glargine U300 and insulin degludec are non-inferior to each other in terms of glycaemic efficacy although hypoglycaemia risk may vary and the choice between them will depend on cost, availability and patient and clinician preference.

\subsection{Real World Studies}


In the DELIVER-D retrospective observational study of data on 1592 patients with T2DM from 39 integrated US healthcare databases, glycaemic efficacy and safety data were collected for patients switching from glargine U100 to glargine U300 or degludec. ${ }^{38}$ As seen in the BRIGHT randomised controlled trial, no significant difference was observed in glycaemic effectiveness or hypoglycaemia incidence or event rates between the two insulin therapies. Another real-world study of 42,001 US patients switching from first generation basal insulins to either insulin glargine U300 or degludec, predictive modelling demonstrated no difference in rates of severe hypoglycaemia between the two newer insulins, providing further reassurance that either one is an appropriate choice in terms of hypoglycaemia data. ${ }^{39}$

\section{Clinical and Practical Considerations}

\subsection{Delivery Device}

Ease and convenience of insulin administration is greatly facilitated by the use of a robust and welldesigned delivery device. Few patients use insulin syringes in the modern era and insulin injection pens which are either disposable or reusable with cartridges are the preferred delivery device. Patient choice with regard to delivery device is important when considering basal insulin therapy provided that the appropriate insulin is selected based on clinical and patient factors. The patient should be given the opportunity to test out the device under healthcare professional supervision to ensure that it is comfortable and used correctly.

Glargine U300 (Toujeo ${ }^{\circledR}$ ) is available in two pen options; SoloStar ${ }^{\circledR}$ which delivers 450 units of insulin per pen in 1 unit increments and Max SoloStar ${ }^{\circledR}$ delivering 900 units per pen in 2 unit increments. ${ }^{40}$ If a patient needs at least 20 units of insulin per day, Max SoloStar ${ }^{\circledast}$ is the recommended device. In a small multicentre German study of 40 insulin and pen-naïve patients with T2DM administering glargine U300 with the SoloStar ${ }^{\circledR}$ pen for 4 weeks, $95 \%$ of participants reported the pen as excellent/good, and generally easy to learn and easy to use and there were no technical problems or adverse events associated with the device. ${ }^{41}$

Degludec $\left(\right.$ Tresiba $\left.^{\circledR}\right)$ is also available in two pen options; FlexTouch ${ }^{\circledR}$ U100 which contains 300 units per pen in 1 unit increments and FlexTouch ${ }^{\circledR}$ U200 which contains 600 units but delivers the same dose in half the volume of the U100 pen and allows 2 unit dose adjustments. ${ }^{42}$ The FlexTouch ${ }^{\circledR}$ pen has a lower injection force, no push-button extension and an end-of-dose click and it was preferred to other insulin pen devices in usability studies in terms of ease of learning and use for patients and teaching to use by healthcare professionals. ${ }^{43}$ 
In a randomised multicentre cross-over study including 42 patients with T2DM and 22 patients with T1DM, 32 nurses and 32 physicians, FlexTouch $100^{\circledR}$ and FlexTouch $200^{\circledR}$ were preferred over SoloStar ${ }^{\circledast}$ for administering injections into a foam cushion at different increasing insulin doses. ${ }^{44}$

\subsection{Patient Adherence to Treatment}

Patient factors such as injection difficulties, lifestyle burden, regimen complexity and inflexibility and practical barriers must all be considered and addressed when choosing appropriate insulin regimens if patient adherence is to be optimised..$^{45}$ Fear of hypoglycaemia is a significant barrier to initiating and maintaining insulin therapy and has been described as "psychological insulin resistance". ${ }^{46}$ Patient education has been shown to improve healthcare behaviours such as treatment adherence and people with T2DM should be strongly encouraged to attend diabetes structured education programmes. ${ }^{47}$ Healthcare providers also need appropriate training on newer insulin therapies, dose adjustment, injection devices and needles to adequately support patients. ${ }^{48}$ The use of simple insulin intensification algorithms can support more rapid escalation of insulin doses to achieve glycaemic targets safely and effectively. ${ }^{49}$ Reducing clinical inertia around initiation and intensification of basal insulin is a key component of optimising insulin therapy. ${ }^{50}$

In the EDITION 1 trial where patients with T2DM who were already on $\geq 42$ units daily of either NPH insulin or glargine U100 with any prandial insulin at baseline were randomised to either glargine U300 or U100 over 6 months, treatment satisfaction scores and did not differ between treatment groups and increased for both insulins by study end. ${ }^{28}$ In EDITION 2, where participants were on basal insulin and oral hypoglycaemic agents before being randomised to either glargine U300 or U100, there were no differences in treatment satisfaction or perceived frequency of hypoglycaemia between the two insulins. ${ }^{29}$ Participant-reported outcomes reported in the EDITION 3 trial of insulin naïve patients with T2DM randomised to either glargine U300 or glargine U100 did not find a difference in health-related quality of life between these insulins and fear of hypoglycaemia decreased with both strengths of insulin over the 6 month study period..$^{30}$ Use of glargine U300 has been shown to be associated with improved quality of life compared with glargine U100.28,30,51

A small qualitative study of 20 adults with T2DM from USA and Switzerland who underwent 90 minute interviews after being on insulin degludec for at least 3 months reported "feeling better", in particular due to greater sense of well-being, enhanced feelings of adaptability and freedom, reduced sense of diabetes burden and increased sense of security especially with regard to hypoglycaemia. ${ }^{52}$

\subsection{Duration of Action}


The duration of action is a critical factor in the effectiveness of basal insulin at maintaining glycaemic targets in the fasting state and overnight. ${ }^{53} \mathrm{NPH}$ insulin has duration of action of around 12-18 hours whereas insulin detemir and glargine are present within the blood stream for up to 24 hours. The ultra-long acting insulins glargine U300 and degludec U100 and U200 have significantly longer durations of action at 32 and 42 hours respectively. ${ }^{54,55} \mathrm{NPH}$ insulin, glargine U100 and detemir are usually administered once or twice daily whereas glargine U300 and degludec U100 and U200 are administered once a day. There is a greater administration window for the ultra-long acting insulins which can be taken within a 4-6 hour period. These characteristics increase flexibility and convenience insulin injections for patients.

\subsection{Timing of Administration and Switching from First Generation Basal Insulins}

The pharmacokinetic profile of concentrated basal insulins allows for a longer window for timing of administration. This can improve patient adherence as it leads to increased flexibility of insulin injections depending on occupational and social circumstances. For glargine U300 the window for insulin administration is up to six hours. ${ }^{28,30}$ The phase 3 clinical trials for glargine U300 showed that hypoglycaemia was most likely to occur between 6.00 am and 10.00 am if administered at bedtime. ${ }^{32}$

In a 26 week study of patients with T2DM who were either insulin-naïve or on insulin glargine U100 were randomised to different pre-specified dosing schedules of insulin degludec allowing for 8 to 40 hour intervals between injections and demonstrated that there was no compromise in glycaemic control or safety with such an exaggerated dosing window for patients on insulin degludec. ${ }^{56}$

Basal insulin is associated with greater insulin treatment satisfaction than prandial insulin. ${ }^{57}$ Glargine U300 is administered once-daily and is available in a pre-filled pen with which up to 80 units can be administered in 1 unit increments. In insulin-naïve patients the recommended starting dose of glargine U300 is 0.2 units per $\mathrm{kg}$ body weight once daily and in those already on insulin therapy, the same unit dose as the previous once-daily intermediate or long-acting insulin can be administered (Figure 2). ${ }^{58}$ However, if the patient is on a twice-daily NPH insulin, it is recommended that $80 \%$ of the total daily $\mathrm{NPH}$ dose is administered for glargine U300 to minimise the risk of hypoglycaemia. Higher doses of glargine U300 are usually required, around $12 \%$ higher by 6 months ${ }^{32}$ and $14 \%$ higher by 12 months ${ }^{59}$ compared with glargine U100, according to clinical trial data.

Insulin degludec U100 and U200 are both administered as once daily injections using pre-filled pens that dose in 1 unit increments, specifically up to 80 units with U100 and up to 160 units with U200 (Figure 2). In insulin-naïve patients, the starting dose of 10 units once daily is recommended whereas those already on insulin therapy can administer the same unit dose as the total daily long or 
intermediate acting insulin unit dose ${ }^{60}$ Notably, no reduction in dose is required if switching between degludec U100 and U200. ${ }^{53}$

\subsection{Patient Groups Most Likely to Benefit}

The choice of basal insulin is determined by a number of insulin factors including glycaemic efficacy, hypoglycaemia risk, weight gain and cost and patient factors such as ease of use, convenience in insulin timings and patient satisfaction. A recent systematic review and network meta-analysis found high-to-moderate evidence that detemir leads to less weight gain compared with all other basal insulins including degludec and glargine U300 and low and very low quality evidence that degludec and glargine U300 were associated with lower incidence of nocturnal hypoglycaemia than detemir and glargine U100. ${ }^{25}$ Significantly this comprehensive meta-analysis of 39 trials including 26,195 participants with T2DM did not find significant evidence that any basal insulins were superior in terms of glycaemic effects or severe hypoglycaemic episodes. It must be noted that insulin degludec had higher rates of severe hypoglycaemia in the SWITCH 2 cross-over randomised controlled cross-over trial than insulin glargine U300 in the EDITION 2 randomised controlled trial. ${ }^{18,29}$

It would be appropriate to consider the second generation basal insulins when recurrent nocturnal hypoglycaemia is affecting the safety and quality of life of a patient with T2DM. Additionally, patients who rely on insulin administration from district or community nursing teams may be appropriate for these insulins because of the prolonged administration windows of 4-6 hours without affecting glycaemic efficacy. Other patient groups likely to benefit from these second generation basal insulins are those with multiple co-morbidities such as cardiovascular disease or chronic renal disease. ${ }^{61}$

\subsection{Potential Dispensing and Administration Errors}

Familiarity with different insulin formulations and strengths is essential if dispensing errors are to be avoided resulting in harm to patients with T2DM. To reduce confusion, various strengths of higher concentration insulins are colour coded differently. Insulin prescribing errors are particularly prevalent during hospital admissions. ${ }^{63}$ Insulin glargine U300 (Toujeo ${ }^{\circledR}$ ) can be easily mistaken for glargine U100 (Lantus ${ }^{\circledR}$ ) and incorrect doses given. Similarly as degludec is available in two strengths, U100 and U200, clear documentation is required to ensure that the correct formulation is prescribed and administered. Appropriate education of patients and carers regarding the type, administration and characteristics of the insulin prescribed will help to minimise insulin-related errors.

\section{Outlook for Future Treatment Options}

Cost is a major factor with regard to future widespread prescription of these highly concentrated basal insulins. Compared with insulin glargine or detemir, degludec is up to $70 \%$ more expensive in some 
European countries such as the UK. ${ }^{10}$ Although glargine U300 has a comparable cost to glargine U100 nearly $15 \%$ higher doses are required to achieve equivalent glycaemic efficacy. ${ }^{59}$ However, it has been estimated that quality of life is improved with insulin degludec in T2DM patients ( 0.0065 qualityadjusted life-years [QALYs] gain) when compared with insulin glargine U100 with an incremental costeffectiveness ratio of $£ 17,939$ and an increased annual cost of $£ 117.63$ An economic evaluation of the DEVOTE trial found that in patients with a high risk of cardiovascular events, degludec was cost-neutral when compared with glargine U100 over two years with a mean improvement of 0.0064 QALYs mainly due to reduced rates of severe hypoglycaemia with degludec. ${ }^{64}$

However, as clinical trials have shown that the main benefit is in reducing hypoglycaemia rather than increased glycaemic efficacy when compared with other basal insulins, there is no indication to choose these insulins as first line in the majority of patients with T2DM.

There is increasing interest in the combination of ultra-long acting insulins with GLP-1 receptor agonists as these formulations reduce hypoglycaemia risk and weight gain and also limit the insulin dose required for the same glycaemic effect. Fixed formulations of these agents such as IDegLira or degludec with liraglutide have been tested in large clinical trials and are now available for use in T2DM. ${ }^{65}$

\section{Conclusion}

Ultimately, successful initiation and intensification of insulin is dependent on appropriate patient selection and education with timely dose adjustment according to dietary patterns, hypoglycaemia, weight and physical activity to reach safe and acceptable glycaemic targets. The second generation ultra-long-acting basal insulins degludec U100 and U200 and glargine U300, which have a greater than 24 hour duration of action, reduced peak action profile and intra-individual and inter-individual variability, represent an incremental benefit in the management of patients with T2DM. The main benefits to patients are their equivalent glycaemic efficacy and safety profile with first generation basal insulins coupled with significant improvements in the flexibility of dose timing and reduced risk of hypoglycaemia especially nocturnal episodes. However, the evidence of these benefits needs further support from high quality randomised controlled trials and observational studies as some controversies remain around the extent of reduction in hypoglycaemia and the fact that degludec in particular represents a relatively expensive option for basal insulin therapy compared with other insulins on the market. The margin of benefit with these second generation insulins may be modest for most patients and therefore careful patient selection and appropriate education and support are important to achieve maximal efficacy and cost-effectiveness. 


\section{Compliance with Ethical Standards}

\section{Acknowledgements}

The authors acknowledge support from the National Institute for Health Research Collaboration for Leadership in Applied Health Research and Care - East Midlands (NIHR CLAHRC - EM), the Leicester Clinical Trials Unit, and the NIHR Leicester Biomedical Research Centre, which is a partnership between University Hospitals of Leicester NHS Trust, Loughborough University and the University of Leicester. No sources of funding were used to assist in the preparation of this article.

\section{Conflicts of Interest}

SC has received speaker fees or educational funding, or both, from Janssen, Eli Lilly, Novo Nordisk, AstraZeneca, and Boehringer Ingelheim and grants in support of investigator initiated trials from Boehringer Ingelheim and Janssen.

KK has acted as a consultant and speaker for AstraZeneca, Novartis, Novo Nordisk, Sanofi-Aventis, Lilly, Merck Sharp \& Dohme, Janssen, and Boehringer Ingelheim, has received grants in support of investigator and investigator-initiated trials from AstraZeneca, Novartis, Novo Nordisk, Sanofi-Aventis, Lilly, Boehringer Ingelheim, Merck Sharp \& Dohme, and Roche, and has served on advisory boards for AstraZeneca, Novartis, Novo Nordisk, Sanofi-Aventis, Lilly, Merck Sharp \& Dohme, Janssen, and Boehringher Ingelheim.

MJD reports personal fees from Novo Nordisk, Sanofi-Aventis, Eli Lilly, Merck Sharp \& Dohme, Boehringer Ingelheim, AstraZeneca, Janssen, Mitsubishi Tanabe Pharma Corporation, and Takeda Pharmaceuticals International and grants from Novo Nordisk, Sanofi- Aventis, Eli Lilly, Boehringer Ingelheim, and Janssen.

\section{List of Figures}

Figure 1 Key Characteristics of Ultra Long Acting Basal Insulins

Figure 2 Flow Chart for Initiating Second Generation Basal Insulin Therapy58,60 


\section{References}

1. Banting FG, Best CH, Collip JB, Campbell WR, Fletcher AA. Pancreatic Extracts in the Treatment of Diabetes Mellitus. Canadian Medical Association journal 1922; 12(3): 141-6.

2. Herring R, Russell-Jones DDL. Lessons for modern insulin development. Diabet Med 2018;35(10):1320-28.

3. Chatterjee S, Khunti K, Davies MJ. Type 2 diabetes. Lancet 2017; 389(10085): 2239-51.

4. Inzucchi SE, Bergenstal RM, Buse JB, et al. Management of hyperglycemia in type 2 diabetes, 2015: a patient-centered approach: update to a position statement of the American Diabetes Association and the European Association for the Study of Diabetes. Diabetes Care 2015; 38(1): 1409.

5. Holman RR, Farmer AJ, Davies MJ, et al. Three-year efficacy of complex insulin regimens in type 2 diabetes. The New England journal of medicine 2009; 361(18): 1736-47.

6. Lipska KJ, Parker MM, Moffet HH, Huang ES, Karter AJ. Association of Initiation of Basal Insulin Analogs vs Neutral Protamine Hagedorn Insulin With Hypoglycemia-Related Emergency Department Visits or Hospital Admissions and With Glycemic Control in Patients With Type 2 Diabetes. JAMA 2018; 320(1): 53-62.

7. Grunberger G, Chen L, Rodriguez A, Tinahones FJ, Jacober SJ, Bue-Valleskey J. A randomized clinical trial of basal insulin peglispro vs NPH in insulin-naive patients with type 2 diabetes: the IMAGINE 6 trial. Diabetes Obes Metab 2016; 18 Suppl 2: 34-42.

8. Munoz-Garach A, Molina-Vega M, Tinahones FJ. How Can a Good Idea Fail? Basal Insulin Peglispro [LY2605541] for the Treatment of Type 2 Diabetes. Diabetes Ther 2017; 8(1): 9-22.

9. International Diabetes F. IDF Diabetes Atlas. Brussels, Belgium, 2017.

10. Standl E, Owen DR. New Long-Acting Basal Insulins: Does Benefit Outweigh Cost? Diabetes Care 2016; 39 Suppl 2: S172-9.

11. Josse RG, Woo V. Flexibly timed once-daily dosing with degludec: a new ultra-long-acting basal insulin. Diabetes Obes Metab 2013; 15(12): 1077-84.

12. Woo VC. New Insulins and New Aspects in Insulin Delivery. Can J Diabetes 2015; 39(4): 33543.

13. Goldman J, Kapitza C, Pettus J, Heise T. Understanding how pharmacokinetic and pharmacodynamic differences of basal analog insulins influence clinical practice. Curr Med Res Opin 2017; 33(10): 1821-31.

14. Garber AJ, King AB, Del Prato $S$, et al. Insulin degludec, an ultra-longacting basal insulin, versus insulin glargine in basal-bolus treatment with mealtime insulin aspart in type 2 diabetes (BEGIN Basal-Bolus Type 2): a phase 3, randomised, open-label, treat-to-target non-inferiority trial. Lancet 2012; 379(9825): 1498-507.

15. Zinman B, Philis T, Cariou B, et al. Insulin degludec versus insulin glargine in insulin-naive patients with type 2 diabetes: a 1-year, randomized, treat-to-target trial (BEGIN Once Long). Diabetes care, 2012;35(12):2464-71.

16. Gough SC, Bhargava A, Jain R et al. Low-volume insulin degludec 200 units/ml once daily improves glycemic control similarly to insulin glargine with a low risk of hypoglycemia in insulinnaive patients with type 2 diabetes: a 26-week, randomized, controlled, multinational, treat-totarget trial: the BEGIN LOW VOLUME trial. Diabetes care, 2013;36(9):2536-42.

17. Onishi Y, Iwamoto Y, Yoo SJ, et al. Insulin degludec compared with insulin glargine in insulinnaive patients with type 2 diabetes: a 26-week, randomized, controlled, Pan-Asian, treat-to-target trial. Journal of diabetes investigation, 2013;4(6):605-12.

18. Wysham C, Bhargava A, Chaykin L, et al. Effect of Insulin Degludec vs Insulin Glargine U100 on Hypoglycemia in Patients With Type 2 Diabetes: The SWITCH 2 Randomized Clinical Trial. JAMA 2017; 318(1): 45-56.

19. Frier BM. How hypoglycaemia can affect the life of a person with diabetes. Diabetes Metab 
Res Rev 2008; 24(2): 87-92.

20. Hammer M, Lammert M, Mejias SM, Kern W, Frier BM. Costs of managing severe hypoglycaemia in three European countries. J Med Econ 2009; 12(4): 281-90.

21. Sinclair A, Dunning T, Rodriguez-Manas L. Diabetes in older people: new insights and remaining challenges. The lancetDiabetes \& endocrinology 2015; 3(4): 275-85.

22. Dalal MR, Kazemi M, Ye F, Xie L. Hypoglycemia After Initiation of Basal Insulin in Patients with Type 2 Diabetes in the United States: Implications for Treatment Discontinuation and Healthcare Costs and Utilization. Adv Ther 2017; 34(9): 2083-92.

23. Ratner RE, Gough SC, Mathieu C, et al. Hypoglycaemia risk with insulin degludec compared with insulin glargine in type 2 and type 1 diabetes: a pre-planned meta-analysis of phase 3 trials. Diabetes Obes Metab 2013; 15(2): 175-84.

24. Vora J, Christensen T, Rana A, Bain SC. Insulin degludec versus insulin glargine in type 1 and type 2 diabetes mellitus: a meta-analysis of endpoints in phase 3a trials. Diabetes therapy : research, treatment and education of diabetes and related disorders 2014; 5(2): 435-46.

25. Madenidou AV, Paschos P, Karagiannis T, et al. Comparative Benefits and Harms of Basal Insulin Analogues for Type 2 Diabetes: A Systematic Review and Network Meta-analysis. Ann Intern Med 2018;169(3);165-174.

26. Marso SP, McGuire DK, Zinman B, et al. Efficacy and Safety of Degludec versus Glargine in Type 2 Diabetes. The New England journal of medicine 2017; 377(8): 723-32.

27. Becker RH, Nowotny I, Teichert L, Bergmann K, Kapitza C. Low within- and between-day variability in exposure to new insulin glargine $300 \mathrm{U} / \mathrm{ml}$. Diabetes Obes Metab 2015; 17(3): 261-7.

28. Riddle MC, Bolli GB, Zieman M et al. New insulin glargine 300 units $/ \mathrm{mL}$ versus glargine 100 units $/ \mathrm{mL}$ in people with type 2 diabetes using basal and mealtime insulin: glucose control and hypoglycemia in a 6-month randomized controlled trial (EDITION 1). Diabetes care, 2014;37(10):2755-62.

29. Yki-Jarvinen $H$, Bergenstal $R$, Ziemen $M$, et al. New insulin glargine 300 units/mL versus glargine 100 units $/ \mathrm{mL}$ in people with type 2 diabetes using oral agents and basal insulin: glucose control and hypoglycemia in a 6-month randomized controlled trial (EDITION 2). Diabetes care, 2014;37(12):3235-43.

30. Bolli GB, Riddle MC, Bergenstal RM et al. New insulin glargine $300 \mathrm{U} / \mathrm{ml}$ compared with glargine $100 \mathrm{U} / \mathrm{ml}$ in insulin-naïve people with type 2 diabetes on oral glucose-lowering drugs: a randomized controlled trial (EDITION 3). Diabetes, obesity \& metabolism, 2015;17(4):386-94. 31. Terauchi $Y$, Koyama $M$, Cheng $X$, et al. New insulin glargine $300 \mathrm{U} / \mathrm{ml}$ versus glargine 100 $\mathrm{U} / \mathrm{ml}$ in Japanese people with type 2 diabetes using basal insulin and oral antihyperglycaemic drugs: glucose control and hypoglycaemia in a randomized controlled trial (EDITION JP 2). Diabetes, obesity \& metabolism, 2016;18(4):366-74.

32. Ritzel R, Roussel R, Bolli GB, et al. Patient-level meta-analysis of the EDITION 1, 2 and 3 studies: glycaemic control and hypoglycaemia with new insulin glargine $300 \mathrm{U} / \mathrm{ml}$ versus glargine $100 \mathrm{U} / \mathrm{ml}$ in people with type 2 diabetes. Diabetes Obes Metab 2015; 17(9): 859-67.

33. Investigators OT, Gerstein HC, Bosch J, et al. Basal insulin and cardiovascular and other outcomes in dysglycemia. The New England journal of medicine 2012; 367(4): 319-28.

34. Lonn EM, Bosch J, Diaz R, et al. Effect of insulin glargine and n-3FA on carotid intima-media thickness in people with dysglycemia at high risk for cardiovascular events: the glucose reduction and atherosclerosis continuing evaluation study (ORIGIN-GRACE). Diabetes care 2013; 36(9): 246674.

35. Rosenstock J, Cheng A, Ritzel R, et al. More Similarities Than Differences Testing Insulin Glargine 300 Units/mL Versus Insulin Degludec 100 Units $/ \mathrm{mL}$ in Insulin-Naive Type 2 Diabetes: The Randomized Head-to-Head BRIGHT Trial. Diabetes Care 2018;41(10):2147-2154.

36. Yamabe $M$, Kuroda M, Hirosawa Y, Kamino H, Ohno H, Yoneda M. Comparison of insulin glargine $300 \mathrm{U} / \mathrm{mL}$ and insulin degludec using flash glucose monitoring: A randomized cross-over study. J Diabetes Investig 2018; Jul 10. doi: 10.1111/jdi.12894. [Epub ahead of print]. 
37. Kawaguchi Y, Sawa J, Sakuma N, Kumeda Y. Efficacy and safety of insulin glargine $300 \mathrm{U} / \mathrm{mL}$ vs insulin degludec in patients with type 2 diabetes: A randomized, open-label, cross-over study using continuous glucose monitoring profiles. J Diabetes Investig 2018; Jun 26. doi:

10.1111/jdi.12884. [Epub ahead of print].

38. Sullivan SD, Bailey TS, Roussel R, et al. Clinical outcomes in real-world patients with type 2 diabetes switching from first- to second-generation basal insulin analogues: Comparative effectiveness of insulin glargine 300 units $/ \mathrm{mL}$ and insulin degludec in the DELIVER D+ cohort study. Diabetes Obes Metab 2018; 20(9): 2148-58.

39. Meneghini L, Roussel R, Zhou FL, et al. Comparable Rates of Severe Hypoglycemia in People with Type 2 Diabetes (T2DM) at High Risk of Hypoglycemia Switching to either Insulin Glargine 300 $\mathrm{U} / \mathrm{mL}$ (Gla-300) or Insulin Degludec (IDeg)-The Lightning Real-World Predictive Modeling Study. American Diabetes Association; 2018 July 2018; Orlando: ADA; 2018.

40. Sanofi. https://www.toujeo.com/how-to-use-toujeo-insulin (accessed 25/09/2018).

41. Pohlmeier H, Berard L, Brulle-Wohlhueter C, et al. Ease of Use of the Insulin Glargine 300

U/mL Pen Injector in Insulin-Naive People With Type 2 Diabetes. J Diabetes Sci Technol 2017; 11(2): 263-9.

42. NovoNordisk. https://www.tresibapro.com/dosing-and-device/tresiba-flextouch.html (accessed 25/09/2018).

43. Bailey $T$, Campos C. FlexTouch(R) for the delivery of insulin: technical attributes and perception among patients and healthcare professionals. Expert Rev Med Devices 2012; 9(3): 209-17. 44. Pfutzner A, Forst $T$, Niemeyer $M$ et al. Assessment for ease of use and preference of a new prefilled insulin pen (FlexTouch Degludec U100/U200) versus the SoloSTAR insulin pen by patients with diabetes and healthcare professionals. Expert Opin Drug Deliv 2014;1199):1381-9.

45. Peyrot M, Barnett AH, Meneghini LF, Schumm-Draeger PM. Factors associated with injection omission/non-adherence in the Global Attitudes of Patients and Physicians in Insulin Therapy study. Diabetes Obes Metab 2012; 14(12): 1081-7.

46. Krall J, Gabbay R, Zickmund S, Hamm ME, Williams KR, Siminerio L. Current perspectives on psychological insulin resistance: primary care provider and patient views. Diabetes Technol Ther 2015; 17(4): 268-74.

47. Chatterjee S, Davies, M.J., Heller, S., Speight, J., Snoek, F.J., Khunti, K. . Diabetes structured self-management education programmes: a narrative review and current innovations. Lancet Diabetes and Endocrinology 2018;6(2):130-142.

48. Peyrot M, Barnett AH, Meneghini LF, Schumm-Draeger PM. Insulin adherence behaviours and barriers in the multinational Global Attitudes of Patients and Physicians in Insulin Therapy study. Diabet Med 2012; 29(5): 682-9.

49. Riddle MC, Rosenstock J, Gerich J. The treat-to-target trial: randomized addition of glargine or human NPH insulin to oral therapy of type 2 diabetic patients. Diabetes care 2003; 26(11): 3080-6. 50. Khunti K, Nikolajsen A, Thorsted BL, Andersen M, Davies MJ, Paul SK. Clinical inertia with regard to intensifying therapy in people with type 2 diabetes treated with basal insulin. Diabetes Obes Metab 2016; 18(4): 401-9.

51. Yki-Jarvinen H, Bergenstal RM, Bolli GB, et al. Glycaemic control and hypoglycaemia with new insulin glargine $300 \mathrm{U} / \mathrm{ml}$ versus insulin glargine $100 \mathrm{U} / \mathrm{ml}$ in people with type 2 diabetes using basal insulin and oral antihyperglycaemic drugs: the EDITION 2 randomized 12-month trial including 6-month extension. Diabetes, obesity \& metabolism 2015; 17(12): 1142-9.

52. Weatherall J, Polonsky WH, Lanar S, et al. When insulin degludec enhances quality of life in patients with type 2 diabetes: a qualitative investigation. Health Qual Life Outcomes 2018; 16(1): 87.

53. Heise T, Mathieu C. Impact of the mode of protraction of basal insulin therapies on their pharmacokinetic and pharmacodynamic properties and resulting clinical outcomes. Diabetes Obes Metab 2017; 19(1): 3-12.

54. Becker RH, Dahmen R, Bergmann K, Lehmann A, Jax T, Heise T. New insulin glargine 300 Units . $\mathrm{mL}-1$ provides a more even activity profile and prolonged glycemic control at steady state 
compared with insulin glargine 100 Units . mL-1. Diabetes Care 2015; 38(4): 637-43.

55. Heise T, Hovelmann U, Nosek L, Hermanski L, Bottcher SG, Haahr H. Comparison of the pharmacokinetic and pharmacodynamic profiles of insulin degludec and insulin glargine. Expert Opin Drug Metab Toxicol 2015; 11(8): 1193-201.

56. Meneghini L, Atkin SL, Gough SC, et al. The efficacy and safety of insulin degludec given in variable once-daily dosing intervals compared with insulin glargine and insulin degludec dosed at the same time daily: a 26-week, randomized, open-label, parallel-group, treat-to-target trial in individuals with type 2 diabetes. Diabetes care 2013; 36(4): 858-64.

57. Farmer, AJ, Oke J, Stevens R, Holman RR. Differences in insulin treatment satisfaction following randomized addition of biphasic, prandial or basal insulin to oral therapy in type 2 diabetes. Diabetes, obesity \& metabolism, 2011;12(12);1136-41.

58. Sanofi. Toujeo SMPC. 03/2018. http://products.sanofi.us/toujeo/toujeo.pdf (accessed 25/09/2018.

59. Ritzel R, Roussel R, Giaccari A, Vora J, Brulle-Wohlhueter C, Yki-Jarvinen H. Better glycaemic control and less hypoglycaemia with insulin glargine $300 \mathrm{U} / \mathrm{mL}$ vs glargine $100 \mathrm{U} / \mathrm{mL}$ : 1-year patientlevel meta-analysis of the EDITION clinical studies in people with type 2 diabetes. Diabetes Obes Metab 2018; 20(3): 541-8.

60. NovoNordisk. Tresiba SmPC. https://www.novo-pi.com/tresiba.pdf (accessed 25/09/2018). 61. Bilal A, Pratley RE. Cardiovascular Outcomes Trials Update: Insights from the DEVOTE Trial. Curr Diab Rep 2018; 18(11): 102.

62. NHS Digital. National Diabetes Inpatient Audit (NaDIA), 2017.

63. Evans M, Mehta R, Gundgaard J, Chubb B. Cost-Effectiveness of Insulin Degludec vs. Insulin Glargine U100 in Type 1 and Type 2 Diabetes Mellitus in a UK Setting. Diabetes Ther 2018;9(5):191930.

64. Pollock RF, Valentine WJ, Marso SP, et al. DEVOTE 5: Evaluating the Short-Term Cost-Utility of Insulin Degludec Versus Insulin Glargine U100 in Basal-Bolus Regimens for Type 2 Diabetes in the UK. Diabetes Ther 2018; 9(3): 1217-32.

65. Gough SC, Bode B, Woo V et al. Efficacy and safety of a combination of insulin degludec and liraglutide (IDegLira) in patients with Type 2 diabetes after 1 year of treatment. Diabetic medicine, 2015;2(11):885-93. 


\section{No action peak}

Reduced intraindividual and interindividual variability

Reduced risk of hypoglycaemia especially nocturnal episodes compared with insulin glargine U100

Increased window of administration (4-6 hours)

Glargine U300

Degludec U100/U200

Non-inferior glycaemic efficacy compared with glargine U100
No safety concerns regarding cardiovascular disease or cancer 
Table 1 Randomised Controlled Trials for Insulin Degludec in Patients with Type 2 Diabetes

\begin{tabular}{|c|c|c|c|c|c|c|c|c|}
\hline Trial & $\mathbf{n}$ & Participants & Duration & Active treatment & Comparator & Glycaemic Efficacy & Hypoglycaemia & Adverse Events \\
\hline $\begin{array}{l}\text { BEGIN Basal-Bolus } \\
\text { Type } 2^{14}\end{array}$ & 755 & $\begin{array}{l}\text { T2DM, treated with } \\
\text { any insulin regimen } \pm \\
\text { oral glucose-lowering } \\
\text { therapy except GLP-1 } \\
\text { analogues or } \\
\text { rosiglitazone }\end{array}$ & 52 weeks & $\begin{array}{l}\text { Insulin degludec U100+ } \\
\text { aspart }\end{array}$ & $\begin{array}{l}\text { Insulin glargine } \\
\text { U100 + aspart }\end{array}$ & $\begin{array}{l}\text { Mean HbA1c reduction } 1.1 \% \\
\text { degludec } 1.2 \% \text { glargine (ETD } \\
0.08 \%, 95 \% \mathrm{Cl}-0.05 \text { to } 0.21 \text { ) } \\
\text { confirming non-inferiority; } \\
\text { mean FPG reduction } 2 \cdot 3 \\
\mathrm{mmol} / \mathrm{L} \text { with degludec and } 2.0 \\
\mathrm{mmol} / \mathrm{L} \text { with glargine } \\
\text { (ETD }-0.29 \mathrm{mmol} / \mathrm{L}[-0.65 \text { to } \\
0.06] ; \mathrm{p}=0.1075\end{array}$ & $\begin{array}{l}\text { Very small numbers of } \\
\text { severe hypoglycaemia } \\
\text { (not analysed). Rates of } \\
\text { overall confirmed } \\
\text { hypoglycaemia } 11.09 \\
\text { episodes per patient- } \\
\text { year exposure (degludec) } \\
\text { and } 13.63 \text { (glargine) (ETR } \\
0.82 \text { (95\% Cl } 0.69-0.99 ; \\
\text { p } 0 \cdot 035) \text {. Confirmed } \\
\text { nocturnal hypoglycaemia } \\
\text { rates } 1.39 \text { episodes per } \\
\text { patient-year exposure } \\
\text { (degludec) and } 1.84 \\
\text { (glargine); ERR } 0.75 \\
\text { (0.58-0.99, } p=0.0399 \text { ) in } \\
\text { favour of degludec. }\end{array}$ & $\begin{array}{l}\text { Commonest } \\
\text { adverse events } \\
\text { nasopharyngitis, } \\
\text { respiratory tract } \\
\text { infections, } \\
\text { headaches. Mean } \\
\text { weight gain at } \\
\text { study end } \\
\text { similar both } \\
\text { groups ( } 3.6 \mathrm{~kg} \text { [SD } \\
4 \cdot 9] \text { (degludec) } \\
\text { and } 4 \cdot 0 \mathrm{~kg}[4 \cdot 6] \\
\text { (glargine) }\end{array}$ \\
\hline BEGIN Once Long ${ }^{15}$ & 1030 & $\begin{array}{l}\text { T2DM, insulin-naïve } \\
\text { on oral glucose- } \\
\text { lowering therapies } \\
\text { excluding } \\
\text { thiazolidinediones }\end{array}$ & 52 weeks & Insulin degludec U100 & $\begin{array}{l}\text { Insulin glargine } \\
\text { U100 }\end{array}$ & $\begin{array}{l}\text { Mean HbA1c reduction } 1.06 \% \\
\text { (degludec) and } 1.19 \% \\
\text { (glargine) (ETD } 0.09 \% 95 \% \mathrm{Cl} \text { - } \\
0.04 \text { to } 0.22 \text { ) confirming non- } \\
\text { inferiority; mean } \mathrm{FPG} \\
\text { significantly greater with } \\
\text { degludec } \mathrm{U} 100 \downarrow \text { by } \\
3.8 \mathrm{mmol} / / \text { to } 5.9 \mathrm{mmol} / \mathrm{I} \text { and } \downarrow \\
3.3 \mathrm{mmol} / \mathrm{I} \text { to } 6.4 \mathrm{mmol} / \mathrm{l} \text { with } \\
\text { glargine } U 100(\mathrm{ETD}-0.43 \\
\mathrm{mmol} / \mathrm{I} 95 \% \mathrm{Cl}-0.74 \text { to } 0.13 \text {, } \\
\mathrm{p}=0.005 \text { ). }\end{array}$ & $\begin{array}{l}\text { Similar rates of } \\
\text { confirmed } \\
\text { hypoglycaemic episodes } \\
\text { ( } p=0.106) \text { between } \\
\text { treatments. Significantly } \\
\text { lower rates of nocturnal } \\
\text { hypoglycaemia with } \\
\text { degludec }(\downarrow 36 \%) \text { (ETR } \\
0.64,95 \% \mathrm{Cl} 0.42 \text { to } 0.98 \text {, } \\
p=0.038) \text {. Rate of severe } \\
\text { hypoglycaemic episodes } \\
\text { significantly lower with } \\
\text { degludec ( } p=0.017) \\
\text { although few episodes } \\
\text { reported for either } \\
\text { insulin (0.003 vs } 0.023 \\
\text { episodes/PYE). }\end{array}$ & $\begin{array}{l}\text { Commonest } \\
\text { adverse events } \\
\text { nasopharyngitis, } \\
\text { headache and } \\
\text { diarrhoea. Similar } \\
\text { weight gain }(2.4 \mathrm{~kg} \\
\text { degludec, } 2.1 \mathrm{~kg} \\
\text { glargine, } \mathrm{p}=0.28) .\end{array}$ \\
\hline BEGIN Low Volume ${ }^{16}$ & 457 & $\begin{array}{l}\text { T2DM, Insulin-naïve } \\
\text { on metformin } \pm \text { DPP- } \\
\text { IV inhibitor }\end{array}$ & 26 weeks & Insulin degludec U200 & $\begin{array}{l}\text { Insulin glargine } \\
\text { U100 }\end{array}$ & $\begin{array}{l}\text { Mean HbA1c reduction } \\
1.3 \pm 1.01 \% \\
(14.3 \pm 11.0 \mathrm{mmol} / \mathrm{mol}) \\
\text { (mean } \pm \mathrm{SD} \text { ) both treatment } \\
\text { groups; mean FPG reduction } \\
\text { significantly greater with } \\
\text { degludec U200 } \downarrow \text { by } 3.7\end{array}$ & $\begin{array}{l}\text { No episodes of severe } \\
\text { hypoglycaemia either } \\
\text { group; no difference in } \\
\text { overall hypoglycaemia } \\
\text { rates degludec U200 and } \\
\text { glargine U100 were } 1.22 \\
\text { and } 1.42 \\
\text { episodes/patient-year, }\end{array}$ & $\begin{array}{l}\text { No serious } \\
\text { adverse events } \\
\text { reported relating } \\
\text { to either insulin. } \\
\text { Commonest } \\
\text { adverse events } \\
\text { nasopharyngitis } \\
\text { and headaches. }\end{array}$ \\
\hline
\end{tabular}




\begin{tabular}{|c|c|c|c|c|c|c|c|c|}
\hline & & & & & & $\begin{array}{l}\mathrm{mmol} / \mathrm{L}(66.7 \mathrm{mg} / \mathrm{dL}) \text { to } 5.9 \\
\mathrm{mmol} / \mathrm{L}(105.7 \mathrm{mg} / \mathrm{dL}) \text { than } \\
\text { glargine } U 100 \downarrow \text { by } 3.4 \\
\mathrm{mmol} / \mathrm{L}(60.9 \mathrm{mg} / \mathrm{dL}) \text { to } 6.3 \\
\mathrm{mmol} / \mathrm{L}(113.1 \mathrm{mg} / \mathrm{dL}) \text { with } \\
\text { IGlar (ETD }-0.42[95 \% \mathrm{Cl}-0.78 \\
\text { to }-0.06]) .\end{array}$ & $\begin{array}{l}\text { respectively (estimated } \\
\text { rate ratio [ERR] for IDeg } \\
200 \text { units } / \mathrm{mL} / / \mathrm{Glar} 0.86 \\
{[95 \% \mathrm{Cl} 0.58-1.28], \mathrm{P}=} \\
0.46) ; \text { no difference in } \\
\text { nocturnal hypoglycaemia } \\
\text { episodes ( } \mathrm{p}=0.25 \text { ). }\end{array}$ & \\
\hline BEGIN Once Asia ${ }^{17}$ & 435 & $\begin{array}{l}\text { T2DM, insulin-naïve } \\
\text { on SU/glinide and } \\
\text { metformin } \pm \text { DPP-IV } \\
\text { or } \alpha \text {-glucosidase } \\
\text { inhibitors }\end{array}$ & 26 weeks & Insulin degludec U100 & $\begin{array}{l}\text { Insulin glargine } \\
\text { U100 }\end{array}$ & $\begin{array}{l}\text { Mean HbA1c reduction }-1.24 \\
\text { (degludec) and }-1.35 \% \\
\text { (glargine), ETD } 0.11 \% \text { ( } 95 \% \mathrm{Cl} \\
-0.03 \text { to } 0.24 \text { ) indicating non- } \\
\text { inferiority; mean FPG reduction } \\
2.88 \text { (degludec) and } 2.97 \\
\text { mmol/L (glargine) (ETD; IDeg- } \\
\text { IGlar: }-0.09 \mathrm{mmol} / \mathrm{L}[95 \% \mathrm{Cl} \\
-0.41 \text { to } 0.23], \mathrm{P}=0.59 \text { ). }\end{array}$ & $\begin{array}{l}\text { One severe } \\
\text { hypoglycaemia episode } \\
\text { with glargine only. } \\
\text { Overall rate of confirmed } \\
\text { hypoglycaemia (RR } \\
\text { degludec/glargine } 0.82 \\
{[95 \% \mathrm{Cl} 0.60 \text { to } 1.11], \mathrm{p}=} \\
0.20 \text { ); nocturnal } \\
\text { hypoglycaemia } \mathrm{RR} \\
\text { degludec/glargine } 0.62 \\
{[95 \% \mathrm{Cl} 0.38 \text { to } 1.04]} \\
\mathrm{p}=0.07 \text {. }\end{array}$ & $\begin{array}{l}\text { Commonest } \\
\text { adverse events } \\
\text { nasopharyngitis, } \\
\text { upper respiratory } \\
\text { tract infection and } \\
\text { diabetic } \\
\text { retinopathy } \\
\text { similar between } \\
\text { groups. }\end{array}$ \\
\hline SWITCH $2^{18}$ & 721 & $\begin{array}{l}\text { T2DM, at least } 1 \\
\text { hypoglycaemia risk } \\
\text { factor and previously } \\
\text { treated with basal } \\
\text { insulin } \pm \text { oral glucose } \\
\text { lowering therapy }\end{array}$ & 16 weeks & Insulin degludec U100 & $\begin{array}{l}\text { Insulin glargine } \\
\text { U100 }\end{array}$ & $\begin{array}{l}\text { No significant difference in } \\
\text { HbA1c reduction between } \\
\text { degludec and glargine ( } p<0.001 \\
\text { for non-inferiority). }\end{array}$ & $\begin{array}{l}\text { Primary endpoint of } \\
\text { overall symptomatic } \\
\text { hypoglycaemic episodes } \\
\text { were significantly lower } \\
\text { with degludec vs glargine } \\
\text { (185.6 vs } 265.4 \text { PYE, RR } \\
0.70,95 \% \mathrm{Cl} 0.61 \text { to } 0.80 \text {, } \\
\text { p<0.001). Rates of } \\
\text { nocturnal symptomatic } \\
\text { hypoglycaemia degludec } \\
\text { vs glargine } 55.2 \text { vs } 93.6 \\
\text { episodes } / 100 \text { PYE, } \\
\text { RR } 0.58 \text { [95\% Cl } 0.46 \text { to } \\
0.74, p<0.001 \text {. No } \\
\text { significant difference in } \\
\text { rates of severe } \\
\text { hypoglycaemia ( } p=0.35 \text { ). }\end{array}$ & $\begin{array}{l}\text { No significant } \\
\text { difference in } \\
\text { weight change } \\
\text { between degludec } \\
\text { and glargine. } \\
\text { Common adverse } \\
\text { events were } \\
\text { nasopharyngitis } \\
\text { and upper } \\
\text { respiratory tract } \\
\text { infection. }\end{array}$ \\
\hline
\end{tabular}

T2DM, type 2 diabetes mellitus; GLP-1, glucagon-like peptide; SU, sulphonylurea; DPP-IV, dipeptidyl peptidase; FPG, fasting plasma glucose; ETD, estimated treatment difference; Cl, confidence interval; ERR, event rate ratio; $R R$, rate ratio; PYE, patient year of exposure 
Table 2 Randomised Controlled Trials for Insulin Glargine U300 in Type 2 Diabetes

\begin{tabular}{|c|c|c|c|c|c|c|c|c|}
\hline Trial & $\mathrm{n}$ & Participants & Duration & Active Treatment & Comparator & Glycaemic Efficacy & Hypoglycaemia & Adverse Events \\
\hline EDITION $1^{28}$ & 807 & $\begin{array}{l}\text { T2DM, on basal insulin ( } \geq 42 \\
\text { units/day) plus mealtime } \\
\text { insulin }\end{array}$ & 6 months & $\begin{array}{l}\text { Insulin glargine } \\
\text { U300 }\end{array}$ & Insulin glargine U100 & $\begin{array}{l}\text { No significant } \\
\text { difference in LS } \\
\text { mean reduction of } \\
\text { HbA1c between } \\
\text { glargine U300 and } \\
\text { glargine U100 } \\
(0.00 \%, 95 \% \mathrm{Cl}-0.11 \\
\text { to } 0.11) \text { (non- } \\
\text { inferior); no } \\
\text { difference in mean } \\
\text { FPG reduction } \\
\text { between insulins }\end{array}$ & $\begin{array}{l}\text { Confirmed or } \\
\text { severe nocturnal } \\
\text { hypoglycaemia } \\
\text { event reduced } \\
\text { risk with glargine } \\
\text { U300 ( } 36 \% \text { ) vs } \\
\text { glargine U100 } \\
(46 \%)(\text { RR } 0.79 \text {, } \\
95 \% \mathrm{Cl} 0.67 \text { to } \\
0.93, p=0.0045) \text {. }\end{array}$ & $\begin{array}{l}\text { Most common adverse } \\
\text { events infections, } \\
\text { gastrointestinal events and } \\
\text { musculoskeletal } \\
\text { complaints with no } \\
\text { differences between } \\
\text { groups. }\end{array}$ \\
\hline EDITION $2^{29}$ & 811 & $\begin{array}{l}\text { T2DM, on basal insulin ( } \geq 42 \\
\text { units/day) plus oral glucose- } \\
\text { lowering therapy }\end{array}$ & 6 months & $\begin{array}{l}\text { Insulin glargine } \\
\text { U300 }\end{array}$ & Insulin glargine U100 & $\begin{array}{l}\text { No significant } \\
\text { difference in } \\
\text { reduction of HbA1c } \\
\text { (LS mean (SD) } \\
\text { reduction -0.57\% } \\
(0.09 \text { ) for glargine } \\
\text { U300 and -0.56\% } \\
\text { (0.09) for glargine } \\
\text { U100 (mean } \\
\text { difference - } 0.01 \% \text {, } \\
95 \% \mathrm{Cl}-0.14 \text { to } \\
0.12 \text { ); similar } \\
\text { reductions in FPG } \\
\text { for glargine U300 } \\
\text { and glargine U100. }\end{array}$ & $\begin{array}{l}\text { Nocturnal or } \\
\text { severe } \\
\text { hypoglycaemia } \\
\text { event reduced } \\
\text { with glargine } \\
\text { U300 vs glargine } \\
\text { U100 (RR 0.77, } \\
95 \% \text { Cl } 0.61 \text { to } \\
0.99, p=0.038 \text { ). }\end{array}$ & $\begin{array}{l}\text { Commonest adverse } \\
\text { events were infections, } \\
\text { nervous system disorders, } \\
\text { gastrointestinal events and } \\
\text { musculoskeletal } \\
\text { complaints with no } \\
\text { differences between } \\
\text { groups. Weight gain } \\
\text { significantly less with } \\
\text { glargine U300 ( } 0.08 \mathrm{~kg} \text { (SD } \\
3.45) \text { than glargine U100 } \\
(0.66 \mathrm{~kg}(3.01)(p=0.015) .\end{array}$ \\
\hline EDITION $3^{30}$ & 878 & $\begin{array}{l}\text { T2DM, insulin naïve on oral } \\
\text { glucose lowering therapy } \\
\text { (sulphonylureas and } \\
\text { meglitinides discontinued at } \\
\text { randomisation) }\end{array}$ & 6 months & $\begin{array}{l}\text { Insulin glargine } \\
\text { U300 }\end{array}$ & Insulin glargine U100 & $\begin{array}{l}\text { No significant } \\
\text { difference in LS } \\
\text { mean reduction of } \\
\text { HbA1c between } \\
\text { glargine U300 and } \\
\text { glargine U100 } \\
(0.04 \%, 95 \% \mathrm{Cl}-0.09 \\
\text { to } 0.17 \% \text { (non- } \\
\text { inferior); mean } \\
\text { change in FPG }\end{array}$ & $\begin{array}{l}\text { Nocturnal or } \\
\text { severe } \\
\text { hypoglycaemia } \\
\text { event reduced } \\
\text { risk with glargine } \\
\text { U300 (16\%) vs } \\
\text { glargine U100 } \\
(17 \%) \text { (RR 0.76, } \\
95 \% \text { Cl } 0.59 \text { to } \\
0.99) \text {. }\end{array}$ & $\begin{array}{l}\text { Commonest adverse } \\
\text { events infections, cardiac, } \\
\text { musculoskeletal and } \\
\text { gastrointestinal events } \\
\text { with no differences } \\
\text { between groups. Lower } \\
\text { weight gain with glargine } \\
\text { U300 (LS mean increase } \\
0.49 \mathrm{~kg}, 95 \% \mathrm{Cl} 0.14 \text { to } \\
0.83 \mathrm{~kg} \text { ) than glargine U100 }\end{array}$ \\
\hline
\end{tabular}




\begin{tabular}{|c|c|c|c|c|c|c|c|c|}
\hline & & & & & & $\begin{array}{l}\text { greater with } \\
\text { glargine U100 than } \\
\text { U300 (LS mean } \\
\text { difference } 0.39 \% \text {, } \\
95 \% \mathrm{Cl} 0.10 \text { to } \\
0.68 \% \text { ). }\end{array}$ & & $\begin{array}{l}\text { (LS mean increase } 0.71 \mathrm{~kg} \text {, } \\
95 \% \mathrm{Cl} 0.36 \text { to } 1.06 \mathrm{~kg} \text { ) } \\
\text { (NS). }\end{array}$ \\
\hline EDITION JP $2^{31}$ & 241 & $\begin{array}{l}\text { T2DM, on basal insulin and oral } \\
\text { glucose lowering therapy }\end{array}$ & 6 months & $\begin{array}{l}\text { Insulin glargine } \\
\text { U300 }\end{array}$ & Insulin glargine U100 & $\begin{array}{l}\text { No significant } \\
\text { difference in } L S \\
\text { mean reduction of } \\
\text { HbA1c between } \\
\text { glargine U300 and } \\
\text { glargine U100 } \\
(0.10 \%, 95 \% \mathrm{Cl}-0.08 \\
\text { to } 0.27 \%)\end{array}$ & $\begin{array}{l}\text { Nocturnal } \\
\text { confirmed or } \\
\text { severe } \\
\text { hypoglycaemia } \\
\text { event reduced } \\
\text { with glargine } \\
\text { U300 vs glargine } \\
\text { U100 (RR 0.62, } \\
95 \% \text { Cl } 0.44 \text { to } \\
0.88 \text { ). }\end{array}$ & $\begin{array}{l}\text { No significant differences } \\
\text { in adverse events between } \\
\text { groups. Significant } \\
\text { difference in weight, LS } \\
\text { mean change (SE) } \\
\text { between glargine U300 (- } \\
0.6[90.2] \mathrm{kg} \text { ) and glargine } \\
\text { U100 (+0.4[0.2]kg) (LS } \\
\text { mean difference }-1.0(-1.5 \\
\text { to }-0.5 \mathrm{~kg}), \mathrm{p}=0.0003) \text {. }\end{array}$ \\
\hline
\end{tabular}




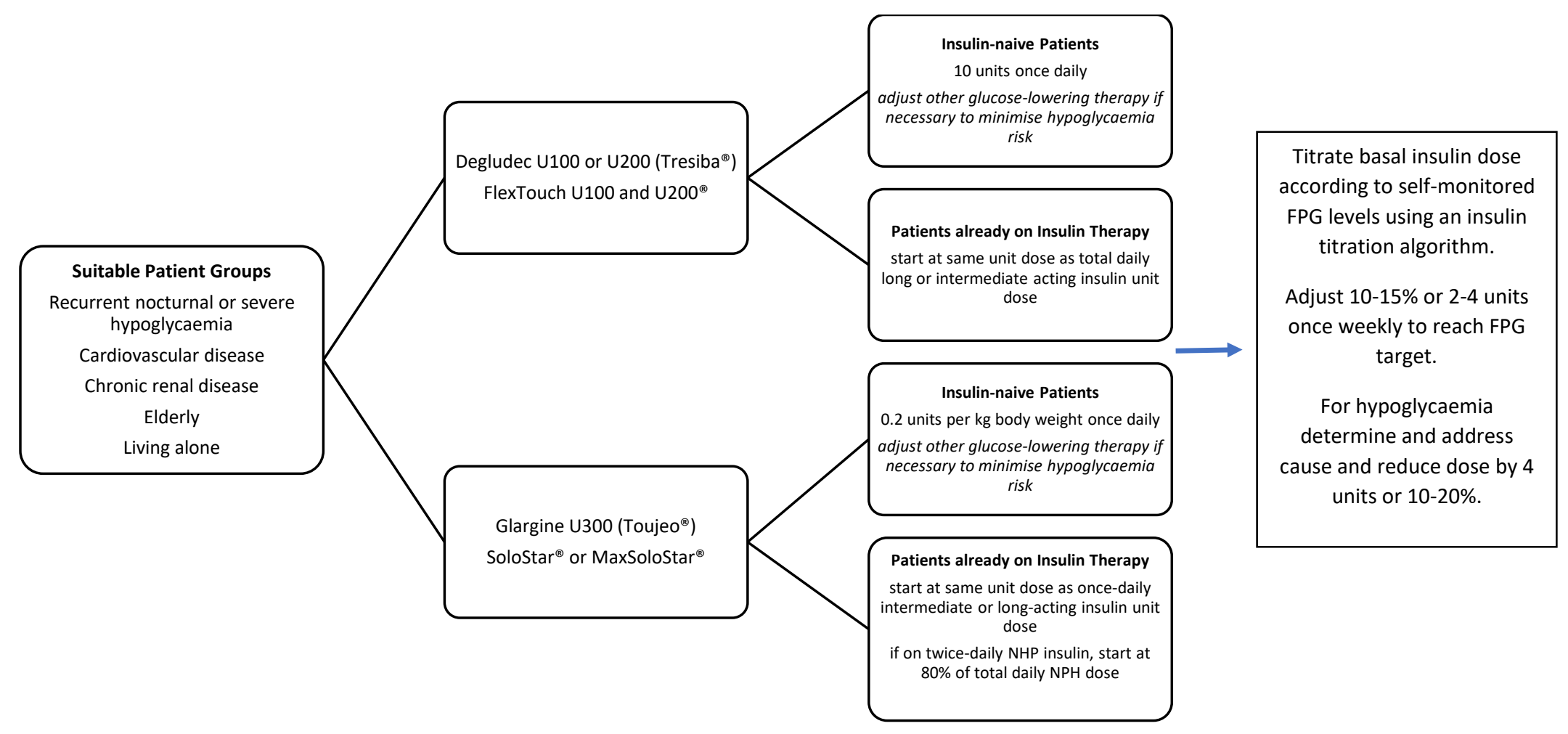


